\title{
An Organizational Systems Perspective to Business Process Modeling in Small to Medium Enterprises (SMEs): a Case of Food Production*
}

\author{
George Papageorgiou ${ }^{1}$, Christos Dimopoulos ${ }^{2}$
}

\begin{abstract}
:
Taking an organizational systems perspective, this paper presents a review to business process modelling and examines the case of food manufacture in a Small to Medium Sized Enterprise (SME), which operates in Cyprus. As a result of the modelling and analysis carried out, areas of concern, issues and opportunities are identified and explored taking into consideration the current business environment of the SME, by focusing on the decision making processes of the production and scheduling activities. The knowledge gained from the modelling effort provides a deeper understanding of the operations and interrelationships between important processes such as "Make", "Buy", "Sell" and "Manage". This proves to be useful for the effective re-design of a production/scheduling decision support system in the particular firm but it also represents the first step towards for the long term development of a generic framework for managerial decision making which takes into consideration the limitations and particularities of manufacturing SMEs.
\end{abstract}

Key Words: Business Process Modeling, Small to Medium Sized Enterprises (SMEs), Decision Support Systems, Production Management, Organizational Change

JEL Classification: $M, L$

\footnotetext{
* Acknowledgement: The research presented in this paper is funded by the Cyprus Research Promotion Foundation's Framework Programme for Research, Technological Development and Innovation 2009-2010 (DESMI 2009-2010, TEXNOLOG/MHXAN/0609(BIE)/05). This framework is co-funded by the Republic of Cyprus and the European Regional Development Fund.

${ }^{1}$ Corresponding Author: EUC Research Center, 6, Diogenous Str., Engomi, P.O. Box: 22006, 1516 Nicosia-Cyprus Tel: +357.22.713000, Fax: +357.22.662051; e-mail: g.papageorgiou@euc.ac.cy.

2 EUC Research Center, 6, Diogenous Str., Engomi, P.O. Box: 22006, 1516 Nicosia-Cyprus Tel: +357.22 .713000 , Fax: +357.22 .662051$
} 


\section{Introduction}

As we are going through the information revolution, a diverse number of philosophies and methods for organizational change of business processes have been developed. These methods aim at supporting modern businesses in their efforts to adapt to the constantly evolving business, social and technological environment. The most common and widely adopted methods range between two philosophical extremes radical change and gradual change. Radical change methods make use of concepts of Business Process Reengineering (Hammer \& Champy, 1993; Hammer \& Hershman, 2010). Gradual change methods utilize the approach of Total Quality Management and Continuous Process Improvement. The methods for implementing this approach come mainly from Deming (2000), Crosby (1992), Feigenbaum (2004), Ishikawa (1991) and Juran (2010).

The various approaches differ in their main objectives, the scope and magnitude of changes expected, in the management techniques used and also in the areas where the change may be applied. However, all these methods have the common characteristic that they require the existence of a solid base upon which to support the development of the ideas they represent. On this basis it is important to provide recording and modelling of how businesses operate to produce either goods or services so as to be able to identify opportunities for change and the design of plausible alternative production systems.

Under this approach, Business Process Modelling was recognized and consolidated as an integral element of any organizational development plan. Numerous tools and techniques proposed and developed to assist with Business Process Modelling. Some of these techniques have received wider recognition and became key components of integrated methodologies such as architectural modelling. The latter, coupled with the rapid development of ICT (Information and Communication Technology), formed the core around, which commercial software packages are structured for modelling of business processes and information systems in an organization.

This paper sets out the definitions of the basic concepts about the theory and practice of modelling of business processes and provides a specific case study of business process modelling carried out in a particular SME in the food production industry. In particular, section 2 presents the basic concepts of Business Process Modelling followed by section 3, which sets the criteria and conditions for selecting an appropriate modelling technique. Section 4 demonstrates how the selected technique of the MIT Process handbook is applied for the modelling the organizational processes for the modelling of the production and scheduling for the case of an SME in the Cyprus food production industry. The SME's business 
processes are identified and analysed in this section. As a result of process modelling, issues and opportunities for improvement are derived. Finally, conclusions are drawn in section 5 and future work is defined.

\section{Basic Concepts of Business Process Modeling}

The creation of business process models is based on human mind processes, which convert knowledge and experiences in a structured and pictorial form. The mind process belongs to problem solving and thus problem definition and problem resolution are an essential part. The human mind creates a partial mental model of a complex problem situation, which requires verification and validation to ensure that reality is truly represented to a satisfactory degree. To achieve effective verification and validation a combination of qualitative and quantitative techniques is necessary.

On the other hand there are constraints imposed for adequate model validation. These include the fact that the symptoms of the problem situation could be misleading. Moreover, the dynamic nature of the problem situation means that the model will be valid only under certain conditions. Also, the difficulty in obtaining adequate information to test the model and the lack of understanding of the holistic nature of the problem, introduce additional constraints.

The usefulness of modeling processes for the design and implementation of organizational changes has been particularly emphasized in the literature. The term Business Process Modeling is used to describe all those activities related to the conversion of available operational knowledge systems into models that describe the specific processes performed by organizations. These models are created for a systematic study in better understanding the main components of an enterprise. Business Process Models also enable their users, to filter unnecessary information that complicate how the company works and thus enable the researcher to focus on areas that really matter. Due to the complex and dynamic nature of organizations, carefully structured models are needed to capture real behavior so as to enable the design of new systems and/or improve the functionality of existing ones.

A business model can then be defined as a symbolic representation of the main components of an organizational system. A model is developed, for understanding, analysis, improvement or replacement of the current organizational system. The organizational system consists of interdependent parts that work together to perform a useful function. The system components can then be any combination of entities such as people, activities, information, software, equipment, products or raw materials. The model should then describe, how the system structure works, what it uses to perform its functions (inputs) and what it produces (outputs). A comprehensive approach to systems analysis with emphasis on the so called soft systems which deal with human activities is provided by Checkland $(2000,2006)$. 
A framework to determine the nature of business processes has been the endeavor of researchers over the last few decades, but a universally accepted framework is yet to be developed. According to Hammer and Champy (1993), pioneers and leading representatives of the BPR, a business process is a set of activities that when they take place in groups, produce a result with value for a customer. A business process can also be defined as a series of logically interrelated tasks performed to implement a defined objective or as a structured, measured set of activities designed to produce a specified output for a particular customer or market.

Further, definitions of business process exist in the literature as follows. Business process modeling is the rationalization of people, materials, energy, equipment and procedures in work activities designed to produce a specific outcome. Business process modeling is the identification of work activities in time and place, with a beginning and an end and clearly defined inputs and outputs. Finally, business process modeling is a group of steps or activities that use people, information and other resources to produce value for an internal or external customer. The steps related in time and place, have a beginning and an end and have inputs and outputs.

Despite the diversity of the above definitions, one can identify some common elements. These are the importance of inputs to achieve a goal or value for a client, the definition of the process as a set of activities and, moreover, the existence of inputs and outputs in each process. Further operational processes, can then be broken down into sub-processes. In the following section specific Business Process Modeling techniques are classified and reviewed.

\section{Classification of Business Modeling Techniques}

Modelling of business processes can be employed in a variety of projects of organizational change but it is especially useful for information systems development, which aim to meet a diverse set of improvement objectives. Business Process Reengineering (BPR) and the design and development of information systems are two common situations where on the first the project seeks a fundamental shift in how a company conducts its business, while on the second ICT is introduced in order to stabilize the organizational system. This resembles the three stage approach of Levin's (1947) organizational change model. The first stage Levin called "unfreezing" as it involved overcoming inertia and dismantling the existing "mind set". In the second stage the actual change occurs, which is typically a period of confusion and transition, where the old ways are being challenged but we do not have a clear picture as to what we are replacing them with yet. Finally, the third and final stage Levin called "freezing", where the new mind set is crystallizing and one's comfort level is returning to previous levels. 
Depending on the objectives set, the business models created should provide users with the necessary information in order to support the achievement of organizational change. Such information can relate to what activities constitute a process, what resources are necessary, when and where the processes are performed, how and why they occur, and what data is imported and exported from the various activities. As concluded by Hammer \& Hershman (2010) the successful design of an end-to-end process can achieve faster cheaper and better outcomes.

To create a realistic business process model a holistic approach should be employed, which takes into consideration functional, behavioural and organizational aspects of the business under study. Further, a functional perspective should be incorporated, which represent particular activities that form a process. A behavioural perspective should also be in understood, which corresponds to the question when the activities are performed, as well as the determination of the flow of the process, that is if the process includes feedback loops, decisions that lead to one or another activity, criteria for entry and exit, etc.. Finally, an Organizational perspective is necessary to represent who performs an activity and the physical technological means and locations used for storing entities and how communication mechanisms are employed.

A key criterion for the classification of modelling techniques is the extent to which they describe the above perspectives. Thus, assessment techniques based on this criterion can be used to select the appropriate technique for a specific project.

Further the modelling technique should be easy to understand and easy to use. In fact usability and reusability (Aldin \& Cesare, 2011) are the most important criteria as they provide the opportunity for comparisons and performance management. The modelling technique should also support the selection of the appropriate technology and capability for scalability and further development. It should further support design justification as well as supervision and coordination in the implementation stages. Process documentation support is also vital criterion. Finally, automation of a business process, support for collaboration among employees, process control and performance management should be supported by the selected technique.

Among the plethora of basic architectures, meta-architectures and integrated methodologies for process modelling the MIT Process Handbook (2012) was selected for further application. The handbook includes the key findings of multidisciplinary researchers at MIT Sloan School of Management. The MIT research team worked for over a ten years to create a comprehensive system for business process modelling. Further, an important characteristic of the handbook is the focus on the process itself, which compatible to the approach of Hammer and Hershman (2010) of an end-to-end process. The handbook also includes a set of representative templates and specific case examples as well as a set of software tools 
for organizing and sharing knowledge which seem quite promising for dealing with system interfaces and interdependencies.

In particular, the selected methodology is utilized for a specific Business Process Reengineering /Information Systems development project for production planning in Cyprus. The next section presents the modelling of the main processes of a particular SME operating in the food production industry of Cyprus. As result of the analysis, important areas of concern and issues as well as opportunities for improvement of the current production/scheduling system are identified.

\section{Process Modeling of the Production and Scheduling System}

This section presents the set of models related to the organizational aspects of the planning \& scheduling environment of the SME "Aphrodite Delights", which operates in the food production industry of Cyprus. The case study presented is part of the IDESME project (http://www.idesme.com), which aims at developing a generic decision support system framework for planning and scheduling operations of SMEs in Cyprus. The set of models focuses on the business aspects of the environment in which the planning and scheduling processes are involved.This case study of business process modelling is based on data collected from interviews with operators, schedulers, supervisors and managerial personnel, as well as direct observation of the work environment "Aphrodite Delights". The study is conducted by the specialized production research team of the IDESME project, which includes the project coordinator, expert in production research, in cooperation with an independent researcher, expert in production research and organizational analysis.

As shown in the following paragraphs a detailed analysis is carried out, of the organizational and control structure of "Aphrodite Delights". The placement of the research team within this structure, as well as the context of the scheduling process is clearly specified. The context in a diagrammatic form will show the flow of information in and out of the process and the related actors that provide or consume this information. The development of these models helps researchers to identify the generic business aspects that should be taken into account while re-designing the organizational processes of the production system. The IDESME project team is planning to also model the scheduling process from a human and technological perspective as the next step.

\subsection{The Modeled SME}

The modelled SME, "Aphrodite Delights" is a company which manufactures traditional Cyprus sweets. It is based in Geroskipou, a town very close to the city of Paphos. The history of Aphrodite Delights dates back to 1895, when the ancestors of current owner George Gavriel produced a particular type of "delight" called 
'Loukoumi', which has proven to be a huge success. The current owner, Geogre Gavriel, took over the management of the company at a very young age in 1990. $\mathrm{Mr}$ Gavriel is an active entrepreneur which very much interested in innovation. Since he took over the management of "Aphrodite Delights" he has been improving, modernizing and expanding its operations on every level. These improvements have been implemented within a rather "hostile" bureaucratic environment and, more recently within the adverse economic situation caused by the world financial crisis. Despite the adverse conditions, "Aphrodite Delights" has accomplished a number of strategic objectives.

From 2007 the majority of the company's operations and manufacturing activities have moved to a new purpose-built factory with modern facilities in the Geroskipou Industrial Area. The company has been awarded with the Protected Geographical Indication (PGI) by the European Union for its "Loukoumi Geroskipou" product. This is the first Cypriot product receiving the award, and the only one internationally for this kind of products. Further, as a result of the implementation of Total Quality Program the company has been awarded with the ISO 22000 food safety standard.

Nevertheless the company is looking forward for further improvements in order to enhance its competitive position in the highly turbulent and dynamic business environment. The focus for improvement is the area of the planning/scheduling processes as this is currently implemented in the production line of the main factory Geroskipou Industrial Area.

\subsection{Business Process Modeling}

As a first step in the business processing modelling effort is the development of a reference model of the business activities of Aphrodite Delights, which will help all stakeholders understand in a better way the "essence" of the business environment in which, the planning / scheduling decisions are being implemented. In addition, the modelling of business processes through the MIT Process Handbook leads "naturally" to a more clear understanding of issues involved through the analysis of the planning and scheduling processes.

The main business processes of "Aphrodite Delights" were modelled using the typical MIT Business Activity Model, as the one depicted in figure 1. 
Fig. 1: The Business Activity Model.

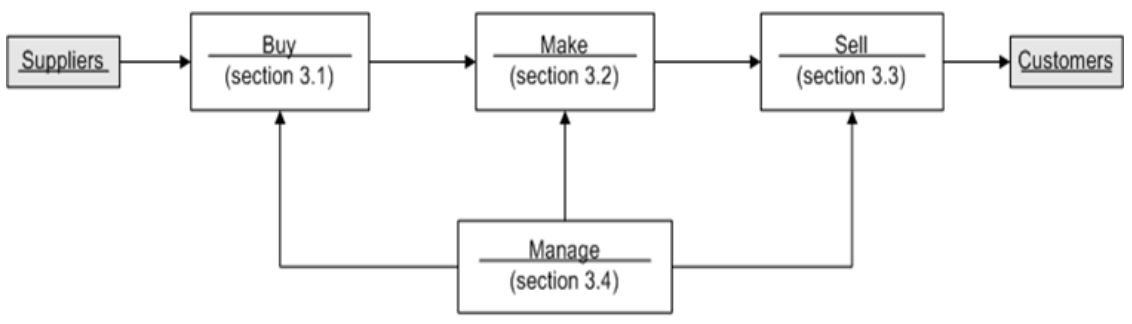

\subsection{The 'Buy' process}

Within the 'Buy' process, the basic manufacturing activities of “Aphrodite Delights" require the purchase of a variety of raw materials. These materials can be arranged into categories of Dietary Raw Materials such as nuts and sugar, Additive Raw Materials such as honey and chocolate, and Packaging Raw Materials such as wrapping and packaging material. These materials become the inputs of the Make Process.

Further as part of the buying process the company uses an extensive network of suppliers in order to acquire its raw materials. Table 1 provides an analysis and evaluation of the most important suppliers, as well as the major characteristics of the raw materials supply process. 
Table 1: Supplier Analysis

\begin{tabular}{|c|c|c|c|c|c|}
\hline & $\begin{array}{l}\text { Supplier } \\
\text { Categories }\end{array}$ & $\begin{array}{c}\text { Types } \\
\text { of materials }\end{array}$ & $\begin{array}{c}\text { Strategic } \\
\text { Importance }\end{array}$ & $\begin{array}{c}\text { Order } \\
\text { Frequency }\end{array}$ & Lead Time \\
\hline i & Tsivingkos & $\begin{array}{l}\text { Sugar } \\
\text { Starch } \\
\text { Nuts } \\
\end{array}$ & $\begin{array}{l}\text { High } \\
\text { High }\end{array}$ & $\begin{array}{l}\text { Weekly } \\
\text { Monthly }\end{array}$ & $\begin{array}{l}1-3 \text { days } \\
1-5 \text { days }\end{array}$ \\
\hline ii & Karkotis & Sugar & High & Weekly & $1-3$ days \\
\hline iii & Kaouris & Sugar & High & Weekly & $1-3$ days \\
\hline iv & Others & Sugars & Medium & Vary rarely & $1-3$ days \\
\hline $\mathrm{v}$ & Frangis & Gum & High & monthly & 1 week \\
\hline $\mathrm{vi}$ & SEDHP & $\begin{array}{c}\text { Peanuts \& } \\
\text { almonds }\end{array}$ & High & Weekly & $1-2$ days \\
\hline vii & Various & Rest of the nuts & & Monthly & \\
\hline viii & Various & Additives & High & Varied & $\begin{array}{l}\text { Ranges from } 1 \\
\text { day to } 2 \text { months }\end{array}$ \\
\hline ix & Kouvas & $\begin{array}{c}\text { Packs, gum pack, } \\
12 \text {-packbox }\end{array}$ & High & $2-4$ per year & 3-4 weeks \\
\hline $\mathrm{x}$ & CyPrint & $\begin{array}{c}\text { Packs (Hex), gum } \\
\text { env. } \\
\text { sticker }\end{array}$ & High & $\begin{array}{l}3-4 \text { per year } \\
1-2 \text { per year }\end{array}$ & $\begin{array}{l}2-3 \text { weeks } \\
2 \text { weeks }\end{array}$ \\
\hline $\mathrm{xi}$ & G.Ioannou & $\begin{array}{c}\begin{array}{c}\text { Inside Nylon } \\
\text { loukoumi }\end{array} \\
\text { Nylon pastelaki } \\
\end{array}$ & $\begin{array}{l}\text { High } \\
\text { High }\end{array}$ & $\begin{array}{l}2-3 \text { months } \\
\text { 3-4 per year }\end{array}$ & $\begin{array}{l}\text { Weekly } \\
2 \text { weeks }\end{array}$ \\
\hline xii & AMS & Paper & High & $2-3$ months & weekly \\
\hline xiii & Pathin & Wrapping & High & monthly & 15 days \\
\hline xiv & & Cartons & High & 3-4 per year & 3 weeks \\
\hline $\mathrm{xv}$ & Barbis & Haroupomelo & High & 2 months & weekly \\
\hline $\mathrm{xvi}$ & Polixeni Christolu & Haroupomelo & High & 2 months & weekly \\
\hline
\end{tabular}

An important remark to note is that the communication with suppliers is mostly done through traditional means such as the telephone. There is currently no IT system which directly connects the inventory system utilized by Aphrodite Delights with its suppliers stock and /or ordering system. Obviously the absence of an online supply chain main chain management would create delays, inaccuracies and most probably unnecessary holding stock.

\subsection{The 'Make' process}

The 'Make' process constitutes the core business process of "Aphrodite Delights", and the one which is the main focus for the IDESME project. This is due to the fact that Make process is based on the execution of planning and scheduling decisions. In our case the decisions are made by the humans with very little input from a computerized information system.

Aphrodite Delights manufactures three main products at its new premises. Additional products manufactured in the old company's premises are not considered 
in this study. Fig. 2 provides a graphical illustration of the company's manufacturing processes in the form of a hierarchical structure diagram.

Fig. 2: Structure diagram of Aphrodite Delights Manufacturing Processes

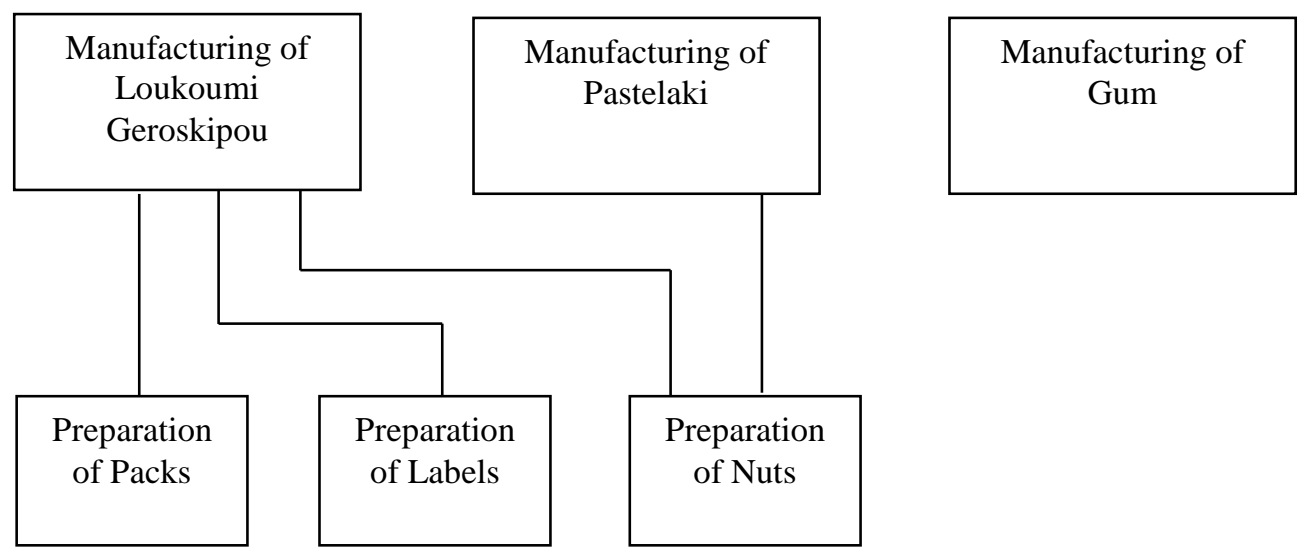

Fig. 2 shows that there are six basic manufacturing processes which take place within the company's premises. We differentiate between (a) main processes, that is, the ones which result in the manufacturing of a company's product and (b) supplementary processes, that is, the ones which result in the manufacturing of items necessary for the implementation of main processes. As shown in Fig. 2 the main processes include the manufacturing of Lokoumi Geroskipou, manufacturing of Pastellaki and Manufacturing of Gum.

Each of these processes is associated with a planning and a scheduling decision. The planning decision results in the determination of the quantity of products which are going to be manufactured. The scheduling decision results in the allocation of resources (machines, humans) to the manufacturing of the planned quantity. These planning / scheduling decisions are not executed with the same frequency, and they do not have the same level of significance for the decision makers. A detailed description of all manufacturing processes, as well as of the associated planning / scheduling decisions implemented by the decision makers, can be further developed.

It is important to note here that decisions are currently made on an intuitive basis. Clearly there will be a great advantage for the efficiency of the manufacturing process the use of a mathematical programming optimization software modeler. The setup of the process in such a software modeler would be easy to implement and the benefits would be quite significant. 


\subsection{The 'Sell' process}

Going to the 'Sell' process “Aphrodite Delights” sells its products to a variety of customers both in bulk and retail form.

In particular the company currently sells its products in retail form to retail shop customers, on-the-spot customers and events customers. Retail shop customers are customers who visit the premises of the Aphrodite's retail shop located in Yeroskipou city. The shop's location is very close (approximately $1 \mathrm{~km}$ ) to the manufacturing facility. On-the-spot customers are customers who visit the manufacturing facility directly. It should be noted that the company has created a retail point of sale within the manufacturing facility, which serves all organized large scale visits from outside groups such as students, tourists etc. Finally, events customers use Loukoumi as a sweet provided in their wedding ceremonies (a Cypriot tradition), or for other social events.

An analysis of the retail customers is provided on Table 2.

Table 2: Retail Customers of Aphrodite Delights

\begin{tabular}{|cccccc|}
\hline & $\begin{array}{c}\text { Retail } \\
\text { Customers } \\
\text { Categories }\end{array}$ & $\begin{array}{c}\text { Types } \\
\text { of products } \\
\text { sold }\end{array}$ & $\begin{array}{c}\text { Order } \\
\text { Priority }\end{array}$ & $\begin{array}{c}\text { Order } \\
\text { Frequency }\end{array}$ & $\begin{array}{c}\text { Order } \\
\text { Quantity }\end{array}$ \\
\hline i & Retail Shop & All products & High & Daily & $\begin{array}{c}\text { Small/ } \\
\text { Medium } \\
\text { ii }\end{array}$ \\
On-the-spot & All products & Not relevant & Not relevant \\
iii & Events & Loukoumi & High & $\begin{array}{c}\text { Seasonally } \\
\text { Varied }\end{array}$ & Varied \\
\hline
\end{tabular}

The company also currently sells its products in wholesale form to main bulk distributors

Main bulk distributors include the 'Kafekopteion Charalambous', which is currently the main bulk distributor of Aphrodite Delight products in the island. The provision of Aphrodite Delights products to this customer is usually done on a daily basis, and the pick-up location is the manufacturing facility. Airport distributors such as 'Akro Markets' currently distribute Aphrodite Delight products to the airports of Larnaca and Paphos. The frequency of orders and the pick-up location is not always fixed. Further, Aphrodite Delights sells its products to various international customers. The frequency of orders is not fixed in this case or for other various bulk customers

An analysis of the retail customers is provided on Table 3. 
International Journal of Economics \& Business Administration, I (2), 2013

George Papageorgiou - Christos Dimopoulos

Table 3: Bulk Customers of Aphrodite Delights

\begin{tabular}{|cccccc|}
\hline Bulk & $\begin{array}{c}\text { Types of } \\
\text { Customers } \\
\text { Categories }\end{array}$ & $\begin{array}{c}\text { Order } \\
\text { products sold } \\
\text { Priority }\end{array}$ & $\begin{array}{c}\text { Order } \\
\text { Frequency }\end{array}$ & $\begin{array}{c}\text { Order } \\
\text { Quantity }\end{array}$ \\
\hline i & Main Bulk & $\begin{array}{c}\text { Loukoumi, } \\
\text { Gum }\end{array}$ & High & $\begin{array}{c}\text { Twice per } \\
\text { week } \\
\text { (Tuesday - } \\
\text { Friday) } \\
\text { Twice per } \\
\text { week }\end{array}$ & Large \\
Varied & Varied \\
ii & Airport & $\begin{array}{c}\text { Loukoumi, } \\
\text { Pastelaki }\end{array}$ & High & High & Varied \\
Liii & Exports & $\begin{array}{c}\text { Pastelaki } \\
\text { All products }\end{array}$ & Varied & Varied & Varied \\
\hline iv & Others & & & & \\
\hline
\end{tabular}

Looking at the above customer analysis, the company could be benefited substantially and improve customer service with the deployment of an inexpensive customer relationship management system which will be linked to the current inventory system. Further the company could be benefited with a business-tobusiness B2B E-commerce system for exchanging transactions electronically with Bulk customers. Also a business to consumer B2C web based system could increase sales significantly.

\subsection{The 'Manage' process}

Going back to Fig. 1 on the business activity model, The Buy, Sell and Make Processes are interconnected with the 'Manage' process which has a coordinating role. The Aphrodite Delights company, due to its small size, operates under a traditional management scheme. The owner, which is also the chief executive of the company, Mr. Gavriel, is responsible for the strategic decisions that need to be taken with regards to the operation of the company. Mr. Gavriel uses external consultants for the improvement of the company's processes, mainly through the company's participation in national research projects. In addition, he participates frequently in international fairs, exhibitions and seminars related to the food industry.

Aphrodite Delights operates under a simple-type organizational structure. As it is widely known from organizational behavior literature, this is the typical organizational and control structure employed by small businesses. Aphrodite Delights is managed top-down and has a centralized, hierarchical structure. The CEO issues commands to lower level management and lower level management provides either information necessary for the implementation of the CEO orders, or provides other feedback to the CEO. There is no explicit formalization of the control structure. Each company's operation might utilize official or semi-official documentation regarding its implementation. In particular, each position in the organizational \& control structure has the following responsibilities. The CEO (as expected in this type of organizational structure) is the central authority of the 
company. He coordinates all operations and he constitutes the principal decision maker. The CEO of Aphrodite Delights also happens to be the single shareholder of the company. This is a common situation for Cypriot SMEs companies of this size. The CEO is currently responsible for quite a high number of tasks and duties discussed below.

Specifically the CEO is responsible for undertaking the major business strategic decisions related to the company's operations. In this way he is defining the main aim as well as the specific objectives of the company's operation. Further, the CEO develops the yearly budget, holds all communications with the company's accountant and the state tax agency, and negotiates the implementation and repayment of loans with the creditor banks. The CEO is also responsible for the planning of new positions and the hiring of new employees (advertising of new positions, implementation of interviews, hiring decision-making, negotiations with prospective employees). He is also responsible for the determination of salary levels for all employees of the company. The CEO also handles marketing by communication with the bulk customers of the company's products. He is responsible of implementing high-level agreements for the distribution of the company's products. He organizes the participation of the company in national and international exhibitions and fairs, promoting the company's products to the broadest possible range of potential customers. The CEO is further responsible for Production Planning and he takes all planning decisions (what will be manufactured) for all company's products. The CEO is also responsible for implementing the all scheduling decisions, in the absence of the Operations' Manager. The CEO submits all Raw Materials Orders needed for the manufacturing of the company's products. The CEO is not directly responsible for taking customer orders from retail or bulk customers of the company, however, he very frequently receives phone orders, especially for ad-hoc products, like the 'Loukoumi Geroskipou sweet' (requires special packaging), which is used in Cypriot wedding ceremonies. He also infrequently receives international mail orders. The CEO conducts research on the development of new company food products, as well as on the improvement of the quality of existing products, through his participation in national and international research projects related to the theme of food engineering. He also participates in research projects which aim to optimize the implementation of specific business processes. The CEO also implements tailor-made improvements (procedural or mechanical) on the manufacturing process of the company's products based on his vast personal experience on the subject. The CEO directly supports the core manufacturing and delivery operations of the company. In particular, he operates the special packaging machine which is employed for the packaging of the Loukoumi Geroskipou sweet (ordered for marriages and similar social events). In addition, he handles the direct delivery of products to specific retail or bulk customers, when this is considered to be necessary. The CEO manages the maintenance of all machinery employed in manufacturing operations. In particular, he schedules the regular 
maintenance periods, and employs the specialized technicians who implement the scheduling tasks. In addition, he organizes all repair works that need to be implemented on broken down machinery. The CEO is responsible for all official and unofficial (written / oral) communication with the state and local agencies, regarding a range of issues which include but are not limited to: applications for support on labor expenses through relevant state support schemes; applications for state support on the participation in local / international exhibitions; applications for the issue / renewal of health certificates; communication with the Social Insurance department; communication with Electricity, Water, and other relevant authorities; coorganization of promotional events in the municipality of Yermasoyia area.

Note that such a heavy work load for the CEO could create problems for the organization especially if the CEO has to be absent at any time period during the operations of the firm. Further this work load could also represent an obstacle to other employees of the company to be more involved in the important operations of the business.

Another main actor of the SME current structure is the secretary of the company. The secretary provides support to the companies' operation through a variety of ways. In particular, the secretary participates in the following business operations. Within the Accounting function the secretary is responsible for issuing all invoices to the company's bulk / retail customers. She is also responsible for the implementation of all handling / housekeeping tasks related to the invoices' paperwork. The secretary uses a standardized software package for the implementation of all accounting-related tasks. The software package automatically updates the company's stock based on the invoices input provided by the secretary, transfers from POS, as well as the relevant production documentation. There is a problem here regarding the inventory system as it is not updated on continuous basis.

Further, the secretary is directly responsible for taking customer orders from retail or bulk customers of the company. The orders can be placed either through phone, or through electronic mail. The secretary is responsible for providing an updated list of current customer orders to the CEO of the company, every time she receives a new order. Again here the absence of a modern CRM system could create inefficiencies, inaccuracies and delays.

The operations' manager of the company is mainly responsible for the flawless implementation of the manufacturing operations of the company. In particular regarding Production Scheduling, the operations manager receives the daily production plan by the CEO, and passes this plan to chief workers who currently implement the corresponding scheduling decisions (allocation of resources over time). Further, the operations' manager overviews the implementation of all tasks 
needed for the manufacturing of the company's products. He ensures that these tasks are executed by the workers in the correct order and in the correct way, as these are specified by the products' specifications. He is responsible for handling any lowlevel problems which can occur at the shop-floor level. If these problems seriously affect the execution of the production plan, then he reports to the CEO of the company, who takes the appropriate decisions. Also the operation's manager compiles all necessary documentation which is necessary for the accreditations that have been achieved by the company (Protected Geographical Information for the 'Loukoumi Geroskipou’ product, and the ISO 22000 food safety standard).

As revealed above the quality control is done on ad hoc basis which leaves room for problems to pass through the production process undetected. A more formal statistical control system could be employed here to improve both quality and productivity.

The stock manager of the company is mainly responsible for the general management of stock. In addition he supports additional operations which are mainly tackled by the company's secretary. The stock manager is responsible for keeping track of the existing stock levels regarding raw materials and finished products. He reports current stock values to the CEO of the company and the company's secretary. The stock manager also assists the company's secretary in receiving orders from retail customers through the Retail-Shop. The company has created (and is currently operating) a retail shop inside the company's main manufacturing premises. The aim of this shop is to sell all company's products to retail customers visiting the premises either as school visitors, tourists, or simply as random customers. The stock manager is responsible for implementing all necessary tasks for the flawless operation of the retail shop. As noted above the company could be benefited by the use of modern Just in Time operations and keep stock at the necessary minimum.

The working force is mainly responsible for the implementation of all manufacturing processes necessary for the manufacturing of the company's products. In addition, a number of workers are responsible for generating the scheduling of resources, based on the production plan conveyed to them via the Operations Manager.

The company could also be benefited by the introduction of team based mechanisms such as quality circles or regular meetings involving assembly line workers where new ideas and problems of the production process are discussed. This will enhance the identification of and solution of problems but also would increase morale and employee engagement. 


\section{Conclusion}

This paper reviews the problem of Business Process Modelling from an organizational systems perspective. The problem of production planning and scheduling is examined for a particular SME. This is used as case study for developing a generic framework for production planning and scheduling decision making as part of the IDESME project.

Carrying out a review of current methodologies in Business Process Modelling and by direct experience gained with the actual implementation of the MIT Process handbook, the IDESME research team made the first step towards the development of a framework process for the interdisciplinary design and implementation of novel production scheduling DSS for Cypriot Small to Medium Enterprises (SMEs). In this way SMEs can gain a significant competitive advantage by utilizing systems that have been designed to adapt to the interdisciplinary realities of their particular production environment. The envisaged framework could form the basis of a common language platform for the employees and management of an organisation, its stakeholders, developers and consultants so that the chances for a successful Decision Support Systems Development are significantly increased.

As shown in this paper the application of the particular technique of the MIT Process handbook proved to be quite fruitful. Through business process modelling we gained a significant insight to the organizational business processes so that a high level of understanding of how a particular SME operates has been achieved. This proves to be imperative for the design of any new improved process and especially for innovation and automation purposes.

As a result of the critical analysis carried out, opportunities for potential improvement have been identified. These include automation and optimization in handling customers and suppliers as well as automating and streamlining the internal processes especially in the area of planning and production. The opportunities can only be undertaken as long as top management commits to implement change. The main criterion for successful implementation would then be the development of trust between management and employees.

However, it is important to note that the organizational perspective is not adequate for completely understanding the complexity involved in today's organizations. In order to have a more holistic view to the problem situation of planning and scheduling in SMEs the authors and the IDESME research team will be examining the business processes from a human-cognitive perspective as well as technological perspective. Such a holistic socio-technical view will allow the identification of tasks and issues to be resolved in the design of a new business process of planning and scheduling. 


\section{References}

Aldin, L. and Cesare, S. (2011), “A literature review on business process modelling: new frontiers of reusability”, Enterprise Information Systems, Vol. 5, Iss. 3.

Checkland, P.B. and Poulter, J. (2006), "Learning for Action: A short definitive account of Soft Systems Methodology and its use for Practitioners, teachers and Students”, Wiley, Chichester. ISBN 10 0-470-02554-9.

Checkland, P.B. (2000), "Soft Systems Methodology: A thirty year retrospective”, Systems Research and Behavioral Science.

Crosby, P. (1992), “Quality Is Free: The Art of Making Quality Certain”, Mentor Books.

Deming, W. E. (2000), “Out of the Crisis”, The MIT Press Ishikawa, Kaoru. What is Total Quality Control? The Japanese Way (1985).

Feigenbaum, A.V. (2004), “Total Quality Control”, 4th edition, McGraw-Hill Professional.

Hammer, M. and Champy, J.A. (1993), "Reengineering the Corporation: A Manifesto for Business Revolution”, New York: Harper Business Books.

Hammer, M. and Hershman, L. (2010), "Faster Cheaper Better: The 9 Levers for Transforming How Work Gets Done”, Crown Business, 1 end.

I-DESME website (2012), available at: http://www.idesme.com / [Accessed 12 June 2012].

Ishikawa, K. (1991), "What is Total Quality Control?”, Prentice Hall Trade

Juran, J. M. (2010), “Juran’s Quality Handbook”, 6th edition, McGraw-Hill Professional; (1989)

Lewin, K. (1947), "Frontiers in group dynamics: Concept, method and reality in social science; social equilibria and social change”, Human Relations, 1(1), 5-41.

MIT Process Handbook (2012), available at: http://process.mit.edu/ [Accessed 12 June 2012].

Thalassinos, I.E. and Zampeta, V. (2012) "How Corporate Governance and Globalization Affect the Administrative Structure of the Shipping Industry”, Journal of Global Business and Technology, Vol. 8(1), 48-52.

Thalassinos, I.E., Havlíček, K. and Berezkinova, L. (2012), "Innovation Management and Controlling in SMEs”, European Research Studies Journal, Vol. XV(4), Special issue, 110-123. 
International Journal of Economics \& Business Administration, I (2), 2013

114 George Papageorgiou - Christos Dimopoulos 